\title{
Spectres of Paper: Writing, Digitization, and the End(s) of the Book
}

\author{
Tadeusz Rachwal \\ SWPS University of Social Sciences and Humanities in Warsaw \\ trachwal@swps.edu.pl
}

Received 6 May 2017; accepted 15 October 2017.

\begin{abstract}
This paper has been inspired by Jacques Derrida's statement revealing that his philosophical writings were mostly devoted to paper. "I have the impression," he said, "(the impression! - what a word, already) that I have never had any other subject basically, paper, paper, paper" (Derrida, 2005, p. 41). My paper addresses this thrice repeated noun as a name not so much of a material object on which we scribble, but as a space between the spirit and the letter, a space which turns out to be ineradicable even at the time of paper's alleged eradication in the e-textual age, which may be called a fin de livre culture. This end of the book, I argue, is a highly provisional declaration of the beginning of a paperless era of digitized media, which are not quite capable of eradicating various traces and spectres of paper haunting their own theorizations.
\end{abstract}

Keywords: paper; writing; digital; analog; spectral.

Hauntology has been strongly tied to the name of Jacques Derrida mainly in the wake of his Specters of Marx, the book inspired, as he writes, by the first noun-Ein Gespenstappearing in the text of the Communist Manifesto. What seems to have prompted him to speculate on haunting, however, seems to be another kind of spook, the apparition of paper - the phantom which he does not literally read as a ghost, but to whose haunting persistence he implicitly admitted in 2001 in an interview saying, and actually writing, that "I have the impression (the impression! - what a word, already) that I have never had any other subject basically, paper, paper, paper" (Derrida, 2005, p. 41; emphasis in original). This thrice repeated noun along with printing connotations carried by the parenthetically exclaimed impression brings to mind the possibility that paper is not only what we write on, but also something which is itself written, impressed or scribbled as an ineradicable trace which contaminates the innocent whiteness, or blankness, of the page. Saying that he 
has the impression, Derrida does not express any certainty as to the subject of his writing, for in addition to imprinting or stamping, the noun "impression" also strongly alludes to vagueness, elusiveness and haziness which, in turn, bring to mind a haunting spectrality of the italicised subject. Slightly reformulating the sentence one could say that paper haunts Derrida and thus imprints itself as a possession ("I have the impression"), as a property, even a private one, whose disappearance haunted Europe through Karl Marx's Ein Gespenst.

Let us say, provisionally, that paper is impressed, or imprinted, in culture not only as the usually white carrier of writing, but also as the possibility of writing which lives on and survives even now in the epoch of digitization which, for some, is a promise of there being a paperless knowledge, a paperless information, a paperless truth. When Derrida wrote in Of Grammatology about the end of the book, he simultaneously envisioned the beginning of writing in which he saw a liberation of what now could be termed textuality, a liberation of the written against pure presence disguised in the form of the book. For Gayatri Spivak the chapter which announces this beginning ("The End of the Book and the Beginning of Writing") is "full of a slightly embarrassing messianic promise" (Spivak, 1997, p. 1xxxi). The announcement of the end of the book could be called messianic because the revelation of the phonocentric nature of culture and of its repressive treatment of writing were seen, or at least described by Derrida, as "historically necessary events" (Spivak, 1997, p. lxxxi). This alleged historical determinism, however, seems not to be so much a prediction of a future, but rather a statement of fact, of the factuality of writing, and of paper, which for a long time was exorcised by the philosophical phonocentricity in which the materiality of writing, and of paper, were treated exactly as spectral, as the pure visibility hiding the invisible truth which, unlike paper, was to be permanent and eternal.

Perhaps the message was that ours is a paper culture which hides its own vulnerability by way of relegating it to the outside, to paper and writing which, like ghosts, lurk there as threatening to its otherwise immutable fixity and permanence. The end of the book, its approach which Derrida sees as the "death of the civilization of the book" is manifested, or manifests itself, paradoxically not through a disappearance of the book, but "through a convulsive proliferation of libraries" (Derrida, 1997, p. 8) in which books, orderly numbered and catalogued, offer access to knowledge now contained in the huge archive which controls writing, keeps it in place, and through now electronic systems makes writing immediately accessible — makes writing, as it were, speak. Once external and supplementary to speech, writing gained the strength of immediacy which precedes inscription, and which thus precedes paper and comes from within without the necessity of paper's mediation:

And thus we say "writing" for all that gives rise to an inscription in general, whether it is literal or not and even if what it distributes in space is alien to the order of the voice: cinematography, choreography, of course, but also pictorial, musical, sculptural "writing." .. All this to describe not only the system of notation secondarily connected with these activities but the essence and the content of these activities themselves. It is also in this sense that the contemporary biologist speaks of writing and pro-gram in relation to the most elementary processes of information within the living cell. And, finally, whether it has essential limits or not, the entire field covered by the cybernetic program will be the field of writing. (Derrida, 1997, p. 9) 
Having the impression that his subject was "paper, paper, paper," Derrida in a sense posits his writing as an autobiography and himself as paper, the seemingly passive carrier of writing for which some kind of pressing, and thus of violence, is essential - the pressure of a quill, of a pen, or a pencil, the pointed objects about which he wrote in Spurs. Having the impression, carrying it, he in fact posits his writing not to be about writing, thus as it were impersonating paper which he simultaneously claims to be his subject, the subject which he has always had. If Jean-Jacques Rousseau famously wrote in Confessions that he was a book, Derrida seems to be saying that he was paper, the whatness of his subjectivity being but an impression, an imprint on the otherwise blank space whose presence consists in disappearance, in being reduced by writing, marginalized into a margin - the theme which he also took up in White Mythology. Writing devours paper, and the imagined threat of its disappearance in the electronic age, in the age of word processing, has only enhanced the nostalgia for paper whose spectre does live on, reflected in the vocabulary of electronic media. We still write papers, though we can do it without touching paper, and though now I am writing a paper on paper seeing only a keyboard and a screen, the digital kind of existence of this writing posits it as removed from both and situates it within the electronic memory, makes it immaterial and untouchable, exiled. Yet this exile seems to be nothing new and it goes hand in hand with the nostalgia for the unwritten, for the whiteness of innocence always already spoilt by inscription.

Marks left on paper cannot be fully trusted, and Descartes's reduction of being to thinking, performed quite a long time ago, was also an expression of the desire to write without writing, to write in the air, or perhaps in the spirit, without the necessity of touching paper with the tip of the pen. "While I am writing," he wrote in Rules for Direction of the Mind,

at the very moment when the various letters are formed on the paper, it is not only the tip of the pen that moves; there could not be the least movement of this that was not at once communicated to the whole pen; and all these various movements are also described in the air by the top end of the pen; and yet I have not an idea that something real travels from one end of the pen to the other. (Descartes, 1954, p. 161)

The very title of Descartes's text expresses a longing for control of thinking rather than writing, an aspiration to manage the movements of the mind which should not be dispersed. The movements described in the air do not guarantee the certainty of the real, and writing does not guarantee the emptying of the mind of the illusory, the performance of what Michael Oakshott calls the "intellectual purge" which begins Descartes's search (Oakshott, 1962, p. 21). In the time of the digital writing this purge seems, or promises, to have been accomplished by way of virtualization which also carries a promise of final transformation from the written to the virtual, which in the subtitle of Wim Westera's book on the digital turn figures as transformation of our existence (The Digital Turn: How the Internet Transforms Our Existence, 2012). Virtualization figures in his book as an implicit promise of the final transformation, of virtual reality's eventual replacement of our imperfect rootedness in the world of our bodies, minds, of pens and papers. In fact, 
this goes hand in hand with the faith in boundless possibilities of technological advancements which will bring us to another world, the world of simulation offered as a new world of sorts to which we, literally, immigrate:

We disconnect the mind from the body and thereby transfer ourselves from the real world to the simulation. We are real-world immigrants in a simulated realm, where we can interact with other immigrants or with artificial characters without noticing any differences. This would be the ultimate virtual reality because the body is frozen while the brain, which would still be processing sensory data and controlling motor actions, is still active. We might want to keep our brain in a vessel and renounce our brainless body. (Westera, 2012, p. 125)

This world of simulation is one which seems to have been freed from haunting by the origin, a perfect simulation which is freed from nostalgia. If for Baudrillard even geometric simulations of the world were akin "to the nostalgia for living forms that haunts geometry" (Baudrillard, 1989, p. 7), the ultimate virtual reality to which we immigrate should ideally make us immigrants without the haunting memory of the old. This achievement is, for Baudrillard, what is asserted by America, but this assertion can also be seen in what is asserted in the digital program of perfecting reality. Baudrillard's modest vision of us as nostalgic Utopians is strongly undermined by the lack of utopianism in various manifestos of the perfection of the digital. For Baudrillard, "[w]e shall remain nostalgic Utopians, agonizing over our ideals, but baulking, ultimately, at their realization, professing that everything is possible, but never that everything has been achieved. Yet that is what America asserts" (1989, p. 78).

This "American" assertion of the achievement speaks, for example, through the idea of Immersive Virtual Environment technology used in psychology, whose proponents describe the virtual as "the ultimate representational system" allowing the observer "to interact 'naturally' with objects and other individuals within a simulated environment or 'world,' an experience indistinguishable from 'normal reality"' (Loomis, Blascovich, \& Beall, 1999, p. 557). The strength of digital technologies lies in their potential to blur "the distinction between reality and its representation" (Loomis, Blascovich, \& Beall, 1999, p. 557) in a representation which replaces the represented. This assertion, before the digital turn, was discernible in Benoit Mandelbrot's fascination with fractals and the idea of transforming the irregularities of nature through mimicking "reality by purely geometric means" (1977, p. 84) with which he, literally, "attacks irregularity" (1977, p. 12). Such projects express the dream of an ideal philosophical language, the idea itself rooted in Jacques Derrida's critique of metaphysics of presence in which the ideal was also posited virtually, though not through mathematical or, later, digital means.

What is also significant in the attempts at the erasure of the nostalgic is the envisioning of the digital as purer and cleaner than analog representations of reality. The superiority of the digital is rhetorically marked in Westera by the separation of the brain from the body, which suggests that the brain/body opposition is one in which the brain may well stand for mind, soul, and thinking as opposed to the impurity and limitations of the body. The analogue world is rhetorically projected as less perfect, as an ambiguously and linearly represented 
world which the digital representation purges of disturbances and noises. The effects of "digitization," which converts streams "of analog information into digital bits of $1 \mathrm{~s}$ and $0 \mathrm{~s}$ with discrete and discontinuous values" (Kreiss \& Brennen, 2014) are neatly outlined by Daniel Kreiss and Scott Brennen who discuss the problem on Culture Digitally webpage:

As communication scholar Tony Feldman (1997, p. 2) argues, unlike analogue data with "continuously varying values, digital information is based on just two distinct states. In the digital world, things are there or not there, 'on' or 'off'. There are no in-betweens." That digital bits have only two possible values leaves many to argue that, in the words of Robert Pepperell (2003, p. 126), "digital information is discrete and 'clean', whilst analogue information is continuous and 'noisy'." Robinson (2008, p. 21) defines analog as: "smoothly varying, of a piece with the apparent seamless and inviolable veracity of space and time; like space and time admitting infinite subdivision, and by association with them connoting something authentic and natural, against the artificial, arbitrarily truncated precision of the digital (e.g., vinyl records vs. CDs)." (Kreiss \& Brennen, 2014)

Unlike the digital, the analog awakens nostalgias of authenticity and nature, but what lurks in it is the possibility of inadequacy and error. Robert Pepperel, referred to in the above quotation, underlines this proneness to error linking it with the simplicity of digital encoding:

The processing, communication and replication of digital data is much less prone to error than that in an analogue system because of the relative simplicity of the encoding system, which is a string of $1 \mathrm{~s}$ and $0 \mathrm{~s}$. Because the data in an analogue machine is not represented discretely (in the same way as it is in a digital machine), it is much more complex to store and duplicate, with the consequence that error is more likely to creep in. (Pepperel, 2003, p. 126)

This alleged immunity to error is also responsible for the mythization of the perfection of the digital and for the long-standing image of immateriality of digitized information. As Marlene Manoff argues, at the earlier stages of digitization the dominant perception was that of "the immateriality of the digital domain and the related assumption that it was somehow enabling us to transcend matter" (2013, p. 276). This new metaphysical promise is gradually giving way to the realization of the obvious, though rhetorically clouded, material rootedness of digital information and what has begun to be more and more frequently addressed, she claims, is "the need for more materialist thinking" (Manoff, 2013, p. 276). This new materialism consists not only in the realization that the storage of digital information uses space, energy and hardware, but also in the realization of the more distant nature of the material which was only moved away from the sphere of the vision, and not virtualized. "The cloud," for example, "does not virtualize network support, it simply relocates it to distant energy-devouring data centers" (Manoff, 2013, p. 276). Though no longer written on paper, data are not hovering in the air like clouds, and though the name of "the cloud" strongly suggests this possibility, it also refers now to an archive, to a material place where documents and books are stored. The figure of Descartes's writing with its top end of his pen in the air can be brought here as a metaphor of the distancing of the material marks left of paper, the distancing which, however, does not remove the material, the paper, which, as it were, spoils the alleged immateriality of digital information, blurs it with its analog origin. As Wolfgang Ernst claims, however, archive is now a nostalgia 
and "a phantasm surviving from the age of print" (2006, p. 120), the persistence of that phantasm and its resistance to becoming purely virtual may well be called the resistance of paper which spectrally returns in the abused terms, albeit catachretically. A webpage is still a page, and there are documents in the docuverse. The page is, as Jacques Derrida saw it, "primarily a figure of paper (of the book or codex)," noticing in Paper Machine that

the page nowadays continues, in many ways, and not only metonymically, to govern a large number of surfaces of inscription, even where the body of paper is no longer there in person, so to speak, thus continuing to haunt the computer screen and all internet navigations in voyages of all kinds. (Derrida, 2005, p. 46)

Voyages of all kind eventually lead to a library, to an archive, regardless of various declarations of what Manoff calls "the obsolescence of print and the death of the codex" (2013, p. 276). These are advanced, she notices, "as part of the validation and promotion of new digital products. Many library mission statements and planning documents participate in the production of these narratives of digital ascendancy and the supersession of the book" (Manoff, 2013, p. 276). Though the archive has changed, freed itself from the demand of strict ordering and became a virtual "an-archive" (cf. Ernst, 2006, p. 120) of sorts, the analog imperfection returns to it through various figurations of paper, perhaps through some drive of imperfection which contaminates it with vulnerability to spam, viruses, bugs and glitches constituting the dark side of digital culture (cf. Sampson \& Parikka, 2009). Perhaps paradoxically, the new world without paper, which was one of the promises of the multimedial cyberspace, cannot overcome its own anomalies because of paper which reappears, or haunts us, through the technological advances which deny it, which foretell its loss, which write its loss beginning with the techne of writing itself, of leaving signs on paper which, for Descartes, were marks of the uncertainty of the real. These signs were simultaneously signs of moving forward, signs of advance which, as Derrida has tried to show, removed the support of paper, in fact virtualized it:

Every sign on the paper had to be picked up as an advance sign: it foretold the "loss" of a support: the end of the "subjectile" is nigh. That is also, doubtless, where this body of paper has a bodily hold on us. Because if we hold to paper, and will do for a long time to come, if it gets hold of us bodily, and through every sense, and through every fantasy, this is because its economy has always been more than that of a medium (of a straightforward means of communication, the supposed neutrality of a support) — but also, paradoxically . . . that of a multimedia. It has always been so, already, virtually. (Derrida, 2005, p. 42)

The disappearance, or loss, of paper is a part of its economy which is, in fact, governed, again paradoxically, by inevitable reappearance, by a haunting return which is also a return of a disappearance. Hence the multimedial character of paper which Derrida, perhaps surprisingly, ascribes to it. In the virtual space, at least according to Wolfgang Ernst, multimedia are also subject to "loss" in the manner paper is lost in the case of a computer screen. "A close reading of the computer as medium," writes Ernst, "reveals that there is no multimedia in virtual space, only one medium, which basically calculates images, words, sounds indifferently, since it is able to emulate all other media. The term multi-media is a delusion" (2006, p. 108). 
Though digital, multimedia are, as it were, too analog for Ernst. They are streams rather than bits and, perhaps unlike in a truly digital world where, as we have seen, "things are there or not there, 'on' or 'off'" (Pepperell, 2003, p. 126), they are not quite there. If writing on paper harbingers its disappearance, multimedia harbinger the loss of digital space which, like paper, supports appearances at the cost of imperfection. It is in this sense, it seems, that Ernst reads the term multimedia as a betrayal: "The term multi-media is thus an interfacial betrayal on the computer screen: in digital space: the difference between the aesthetic regimes only exists for the human user, simulating the audio-visual human senses under one surface" (2006, p. 108). Between the white surface of paper and the one surface of something which might be called a mono-medium falls the shadow of the senses which "work" analogically, imperfectly regimenting and dividing these two haunting presences into books, texts, pages and webpages in accordance with the aesthetic regimes which we make up by ourselves. This division, or partition, of the sensible (cf. Rancière, 2010), even the partition into pages - be it book-pages or web-pages - is haunted by paper whose smoothness and whiteness is illusory. For paper seems to be multimedially programmed and under its innocent whiteness, "beneath the appearance of a surface, it holds in reserve a volume, folds, a labyrinth whose walls return the echoes of the voice or song that it carries itself; for paper also has the range or the ranges of a voice bearer" (Derrida, 2005, p. 44). It is this program, or rather pro-gramme, the proto-writing of grammatology which does not allow paper to simply become absent and prolongs "the afterlife of paper-far beyond its disappearance or its withdrawal" (Derrida, 2005, p. 46). This pro-gramme includes the possibility of digital programming, though its execution, or performance, is left to Ernst's "human senses," to the analog imperfection which need not be necessarily treated as the revenge of analog (as the title of David Sax's recent book suggests; cf. Sax, 2016) expressed in growing sales of vinyl records and Moleskin notebooks, but rather as a way of reminding that the spectral presence of paper may be an incentive to thinking that paper's complex technological and material history, along with the symbolic history of its projections and interpretations, is "a history tangled up with the invention of the human body and of hominization" (Derrida, 2005, p. 43). Paper did, and does, take part in the making of the human and though in the digital world it is not seen "in person," as Derrida phrased it in one of the above quotations, its spectre haunts not only its origin but also its uses and abuses in the contemporary world which is, as it seems, always already more than one.

\section{References}

Baudrillard, J. (1989). America. (C. Turner, Trans.). London, UK: Verso.

Derrida, J. (1994). Specters of Marx: The state of the debt, the work of mourning and the new international. (P. Kamuf, Trans.). New York, NY: Routledge.

Derrida, J. (1997). Of grammatology. (G. C. Spivak, Trans.). Baltimore, MD: John Hopkins University Press. (Original work published 1967)

Derrida, J. (2005). Paper machine. (R. Bowlby, Trans.). Stanford, CA: Stanford University Press. 
Descartes, R. (1954). Rules for direction of the mind. In E. Anscombe \& P. T. Geach (Eds. \& Trans.), Descartes: Philosophical writings (pp. 153-180). London, UK: Nelson

Ernst, W. (2006). Dis/continuities: Does the archive become metaphorical in multi-media space? In W. Hui Kyong Chun \& T. Keenan (Eds.), New media, old media: A history and theory reader (pp. 105-124). New York, NY: Routledge.

Feldman, T. (1997). An introduction to digital media. New York, NY: Routledge.

Kreiss, D., \& S. Brennen. (2014, September 8). Digitalization and digitization. Culture Digitally. Retrieved April 21, 2017 from http://culturedigitally.org/2014/09/digitalization-and-digitization/

Loomis, J. M., Blascovich, J. J., \& Beall, A. C. (1999). Immersive virtual environment technology as a basic research tool in psychology. Behavior Research Methods, Instruments, \& Computers, 31(4), 557-564.

Mandelbrot, B. B. (1977). The fractal geometry of nature. New York, NY: W.H. Freeman \& Company.

Manoff, M. (2013). Unintended consequences: New materialist perspectives on library technologies and the digital record. Libraries and the Academy, 13(3), 273-282.

Oakeshott, M. (1962). Rationalism in politics and other essays. London, UK: Methuen.

Pepperell, R. (2003). The posthuman condition: Consciousness beyond the brain. Portland, OR: Intellect Books.

Rancière, J. (2010). Dissensus: On politics and aesthetics. (S. Corcoran, Trans.). London, UK: Continuum.

Robinson, D. (2008). Analog. In M. Fuller (Ed.), Software studies: A lexicon (pp. 21-31). Cambridge, MA: MIT Press.

Sampson, T. D., \& Parikka, J. (Eds). (2009). The spam book: On viruses, porn, and other anomalies from the dark side of digital culture. Cresskill, NJ: Hampton Press.

Sax, D. (2016). The revenge of analog: Real things and why they matter. New York, NY: Public Affairs.

Spivak, G. C. (1997). Translator's preface. In J. Derrida, Of grammatology (pp. ix-xc). (G. C. Spivak, Trans.). Baltimore, MD: John Hopkins University Press.

Westera, W. (2012). The digital turn: How the internet transforms our existence. Bloomington, IN: AuthorHouse. 